\title{
SABERES DOS DISCENTES DE ENFERMAGEM SOBRE SEGURANÇA DO PACIENTE: ÊNFASE NA HIGIENIZAÇÃO DAS MÃOS
}

\section{KNOWLEDGE OF NURSING STUDENTS OF SAFETY PATIENT: EMPHASIS ON HAND HYGIENE}

\author{
Rita Neuma Dantas Cavalcante de Abreu*, Carolina de Paula Lima Melo**, Angela Maria \\ Uchoa Rodrigues***, Renata Carneiro Ferreira***
}

Autora para correspondência: Rita Neuma Dantas Cavalcante de Abreu - rita_neuma@yahoo.com.br

*Doutora em Biotecnologia da Universidade Federal do Ceará (UFC). Docente da UNIFOR. Enfermeira do Instituto Dr. José Frota (IJF).

**Enfermeira. Especialista em Enfermagem em Terapia Intensiva pela UNIFOR, Ceará.

***Docente da UNIFOR, Ceará

\section{R E S U M O}

Objetivou-se averiguar os saberes dos discentes de enfermagem sobre higienização das mãos. Estudo descritivo, qualitativo, realizado em uma Universidade de Fortaleza-Ce. Participaram da pesquisa 25 discentes matriculados no último semestre do curso de Enfermagem. $O$ fechamento amostral foi por saturação teórica. A coleta de dados foi realizada entre os meses de setembro a novembro de 2015 . A análise dos dados foi por meio do método de análise de conteúdo proposto por Bardin. Do total dos 25 entrevistados, a técnica de higienização das mãos foi a mais citada como medida básica de segurança para o profissional e paciente. Houve valorização pelos acadêmicos de aspectos farmacológicos, - que pode estar associado à prática de administração de medicamentos. O transporte seguro e cirurgia segura foram pouco citados pelos graduandos. As dificuldades para a realização da técnica de higienização das mãos citadas poderão servir de norte teórico para se elaborar estratégias para que esses dificultadores sejam superados.

PALAVRAS-CHAVE: Enfermagem; Segurança do paciente; Higienização das mãos. 
This study aimed to assess the knowledge of nursing students about handwashing - descriptive, qualitative study, conducted in a University of Fortaleza- Ce. The participants were 25 students enrolled in the last semester of the nursing course. The sample was closed by theoretical saturation. Data collection was carried out between September and November 2015. Data analysis was by the method of analysis of content proposed by Bardin. Of the total of 25 respondents, the cleaning technique of hands was mentioned as a basic measure of security for professional and patient. There was appreciation for academic pharmacological aspects, which may be associated with the practice of drug administration - The safe transport and safe surgery were seldom mentioned by graduate students. The difficulties to carry out the cleaning technique of hands mentioned may serve as a theoretical north to develop strategies for these complicating be overcome.

KEYWORDS: Nursing; patient safety; Handwashing. 


\section{INTRODUÇÃO}

A assistência de enfermagem de maneira segura foi discutida por Florence Nightingale, cujos feitos se encontram registrados em memoráveis publicações, nas quais teceu a reflexão "pode parecer talvez um estranho princípio enunciar como primeiro dever de um hospital não causar mal ao paciente"1. Recentemente, o Ministério da Saúde, ao publicar - manual de segurança do paciente e higienização das mãos, destacou a importância de Florence Nightingale na Guerra da Criméia².

Portanto, há muito se discute a importância da higienização das mãos. Trata-se de uma temática amplamente discutida nos periódicos da saúde e a sua eficácia comprovada por meio de evidências científicas para o controle de infecções relacionadas a assistência a saúde ${ }^{2}$. Não se pode idealizar a assistência de enfermagem, sem pensar em cuidar do paciente de maneira segura e limpa ${ }^{3}$. A adesão a essa prática depende de muitos fatores tais como - conhecimento que 0 aluno apreendeu durante a realização dos cursos de graduação, a sua vivência dos estágios, entre outros ${ }^{4}$.

Diante da importância do assunto abordado, a literatura ${ }^{4}$ tem chamado a atenção para a discussão sobre segurança do paciente entre docentes e discentes dos cursos da área da saúde. As pesquisas ${ }^{4}$ revelam que estudantes superestimam sua adesão às práticas de higienização das mãos.

O interesse em realizar este estudo surgiu devido as discussões realizadas durante a graduação em enfermagem sobre a importância de garantir uma assistência de enfermagem de qualidade. Assim, acreditamos que para que isto aconteça, é necessário seguir as políticas implementadas pelo Ministério da Saúde para a segurança do paciente. Surgindo, assim, alguns questionamentos: Os graduandos de enfermagem conhecem os passos para segurança do paciente? Quais os fatores que dificultam a higienização das mãos pelos acadêmicos? A escolha do curso de enfermagem se deve ao cuidado direto e contínuo que estes futuros profissionais desenvolverão aos pacientes.

Os benefícios esperados com a pesquisa são no sentido de despertar para a importância da discussão das políticas implementadas pelo Ministério da Saúde para a segurança do paciente entre discentes. Objetivou-se averiguar os saberes dos discentes de enfermagem sobre segurança do paciente e higienização das mãos.

\section{METODOLOGIA}

Estudo do tipo descritivo, de natureza qualitativa, realizado em uma Universidade de FortalezaCe. Participaram da pesquisa 25 discentes, regularmente matriculados no último semestre do curso de Enfermagem da instituição de ensino citada acima, idade acima de 18 anos e aceitaram participar espontaneamente do estudo.

Inicialmente, os pesquisadores fizeram um convite aos alunos do último semestre do curso de enfermagem. Foi explicado o objetivo da pesquisa e a escolha em participar ou não da pesquisa. Os discentes que concordaram em assinar o Termo de Consentimento Livre e Esclarecido, foram entrevistados, quando foi aplicado o instrumento de coleta para esta pesquisa. Vale ressaltar, entretanto, que $\circ$ fechamento amostral foi feito por saturação teórica ${ }^{5}$.

A coleta de dados foi realizada entre os meses de setembro a novembro de 2015, quando os participantes responderam as perguntas a saber: Fale sobre os passos para segurança do paciente. Quais os fatores que dificultam a higienização das mãos pelos acadêmicos? Ressalta-se, ainda, que as falas obtidas pela entrevista foram transcritas de forma fidedigna mediante as respostas gravadas dos participantes.

A análise dos dados foi por meio do método de análise de conteúdo proposto por Bardin', observando-se as seguintes etapas: Constituição do corpus; Composição das unidades de análise; Codificação e recortes; Categorização; Descrição das categorias. Os dados permitiram a organização de duas categorias a saber: A enfermagem e a segurança do paciente; Fatores intervenientes na 
Ao longo da pesquisa, os pressupostos da bioética, configurados em sua Resolução ${ }^{7}$ CNS No466, de 12 de dezembro de 201 2: autonomia, não-maleficência, beneficência e justiça foram considerados. Para manter 0 anonimato dos participantes, os recortes dos discursos que ilustram os resultados foram codificados com a letra $A$.

Os participantes do estudo receberam orientações sobre o anonimato, natureza, objetivos e benefícios da pesquisa ${ }^{7}$. O projeto foi encaminhado ao Comitê

\section{RESULTADOS}

Os dados referentes aos saberes dos graduandos de enfermagem sobre segurança do paciente foram apresentados na Figura 1 e organizados segundo os dez passos propostos pelo Conselho Regional de Enfermagem de São Paulo ${ }^{3}$.

Passos de Segurança dos Pacientes

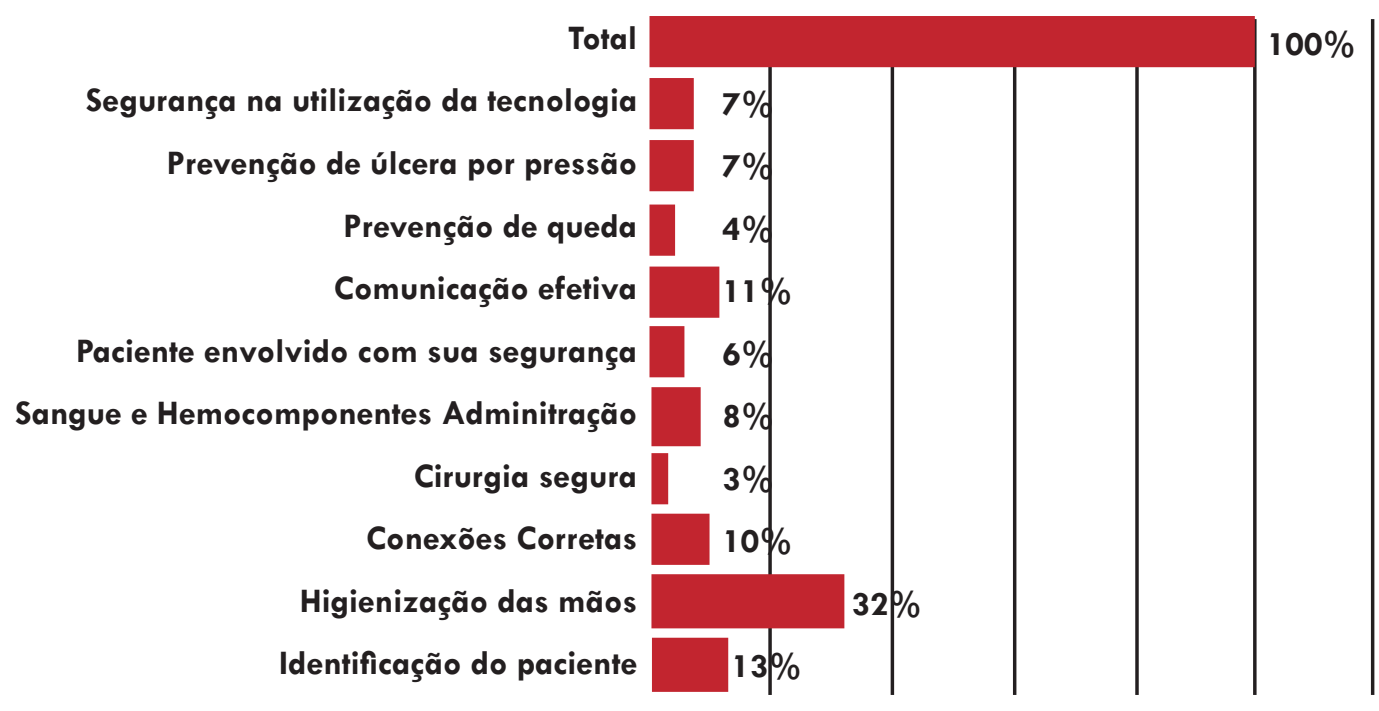

Figura 1: Distribuição dos acadêmicos referente aos saberes dos passos para segurança do paciente, Fortaleza-Ceará, 2015.

A Figura 1 mostrou que do total de 25 entrevistados, a técnica de higienização das mãos prevaleceu (32\%), como uma medida básica de segurança para o profissional e paciente. Cabe ressaltar que alguns estudantes citaram mais de uma medida para a segurança do paciente.

Sobre as duas categorias, têm-se: A enfermagem e a segurança do paciente; Fatores intervenientes na higienização das mãos pelos acadêmicos.

\section{A ENFERMAGEM E A SEGURANÇA DO PACIENTE}

Ao questionar-se sobre os passos para a garantia da segurança do paciente, duas alunas relataram a importância de capacitação dos profissionais para minimização dos danos:

Primeiro, para garantir a segurança do paciente, - profissional precisa estar seguro e assegurado, receber treinamento, conhecimento para que possa evitar danos previsíveis. A segurança do paciente é muito ampla e ao mesmo tempo bem focada, quando me lembro dos termos de ética (imperícia, imprudência e negligência) (A1).

Os passos de garantir segurança do paciente são medidas tomadas pela equipe que visam melhorar a assistência, minimizando erros técnicos (A2).

No entanto, alguns relatos apresentaram cuidados de enfermagem tais como verificação de sinais vitais, técnicas assépticas, entre outros.

Utilizar EPI's, monitorização dos sinais vitais, 
verificar prontuário e prescrições, lavagem das mãos, verificar os 5 certos (A3).

A boa higienização das mãos, o procedimento correto, técnica correta (A4).

Realização da técnica correta e asséptica, conhecimento científico adequado (A5).

Garantir o princípio da biossegurança, dos procedimentos básicos, como lavagem das mãos, técnicas assépticas (A6).

Os relatos demonstraram que os graduandos apreenderam e valorizaram os "certos" para se garantir a administração segura de medicamentos. Vejamos os recordes:

Paciente correto, medicamento correto, leito correto, horário correto (A7).

São 6 passos: medicação certa, paciente certo, via certa, dose certa[...] (A8).

Evidenciaram-se ainda nas falas dos graduandos conceitos farmacológicos como farmacovigilância e tecnovigilância.

Higienização das mãos, identificação correta do paciente, prevenção do risco de quedas, farmacovigilância, tecnovigilância (A9).

Higienização das mãos, prevenção de quedas, vigilância farmacológica, identificação correta do paciente (A10).

\section{FATORES INTERVENIENTES NA HIGIENIZAÇÃO DAS MÃOS PELOS ACADÊMICOS}

Aos serem questionados sobre os fatores que interferem na realização da técnica de higienização das mãos, alguns graduandos referiram que valorizam a técnica. No entanto, existem fatores observados, principalmente nos campos de estágio, que interferem negativamente nessa prática. Vejamos os recortes:

A preocupação, pressa, ansiedade para começar a realizar logo os procedimentos (A11).

Acredito que a cobrança de que se desenvolva a técnica de forma correta mais rápida, dificulta a boa higienização. Somos cobrados a realizar de forma rápida os procedimentos (A13).
Falta de conhecimento dos estudantes sobre os benefícios da higienização das mãos (A12). Nem sempre, porque, às vezes, o tempo não contribui e lavamos de qualquer jeito, sabendo que não é o certo, mas é melhor do que não lavar. Desconhecimento da técnica asséptica, falta de hábito (A6).

[...] penso que direcionamos e supervalorizamos as técnicas e habilidades dos procedimentos práticos, menosprezando a importância da lavagem das mãos. [...] Nem sempre é possível realizar o passo a passo da técnica, porém busco realizar antes e após cada procedimento lavar as mãos, realizo somente toda a técnica dentro do centro cirúrgico nas instrumentações ou em pacientes que estão em isolamento (A 14).

Foi citado pelos estudantes a importância de se garantir equipamentos e insumos para a prática de higienização das mãos:

[...] Lavo constantemente minhas mãos e sempre seguindo os passos da técnica correta, porém, nos estágios, nos decepcionamos ao ver que os profissionais não realizam. [...] Muitos acadêmicos não levam a sério as técnicas corretas, principalmente a lavagem das mãos (A15).

Realizar a higienização das mãos a cada troca de procedimento invasivo e de paciente. A cultura da higienização das mãos vai além da prática estudantil. Sigo sempre. Não existem fatores que dificultem, em cada unidade hospitalar e em postos, encontramos: sabão, pia e na maioria das vezes, a ilustração fixada da lavagem das mãos (A5).

Em primeiro lugar, garantir sabão e papel para a lavagem das mãos, já que em alguns estabelecimentos faltam esses materiais básicos. Em seguida, é importante higienizar desde os dedos, polpas digitais, unhas, dorso da mão, punho (A13).

Sim, pois os alunos estão sedentos por conhecimentos e conhecem a importância de tal técnica, realizando assim a técnica correta até porque estão com as técnicas frescas em sua memória (A7). 


\section{DISCUSSÃO}

A higienização das mãos consiste em um dos maiores desafios para a prevenção das infecções relacionadas ao cuidado em saúde, devido a sua baixa adesão pelos profissionais da área ${ }^{8}$. Isso se relaciona, em parte, com os aspectos comportamentais de cada indivíduo, pois estes são determinantes na atitude de execução ou não do ato de higienizar as mãos ${ }^{8}$.

A administração de medicamentos representa uma das maiores responsabilidades da enfermagem, sobretudo do enfermeiro. Os acadêmicos enfatizaram o seguimento dos "certos" nessa prática como uma estratégia para a segurança do paciente, bem como a higienização das mãos.

Sabe-se que durante a administração de medicamentos, sobretudo pelas vias endovenosa e intramuscular, rompe-se a primeira barreira de proteção, que é a pele. Assim, torna-se necessário $\circ$ uso de medidas preventivas?. Diante do exposto, em um estudo, identificou-se que as medidas complementares à anti-sepsia da pele do paciente, tais como a higienização das mãos pelos profissionais antes de realizar o procedimento, não foi valorizada pelos mesmos?

Conforme explicitado, conceitos de farmacovigilância e Tecnovigilância também apareceram dos discursos. Com a contínua incorporação de tecnologias na saúde, o gerenciamento de risco hospitalar deve ser implantado para sistematizar o monitoramento de eventos adversos, com ações para o controle e eliminação de seus danos. Assim, a tecnovigilância atua nos procedimentos para aquisição, utilização e controle da qualidade de produtos e equipamentos na saúde. Ressalta-se ainda outras áreas, como Farmacovigilância (vigilância de medicamentos) e Hemovigilância (vigilância de hemocomponentes) ${ }^{10}$. Os dados sugerem que os inúmeros procedimentos a serem realizados num ambiente hospitalar, em um período curto de tempo, pode contribuir para a baixa adesão da higienização das mãos.

Os fatores intervenientes para higienização das mãos citados pelos graduandos tais como: a preocupação; pressa para se começar a realizar os procedimentos e desconhecimento de alguns estudantes sobre os benefícios da prática de HM também foram encontrados em outros trabalhos científicos". A "pressa" poderá comprometer a técnica de $\mathrm{HM}$ que exige uma sequência correta.

Segundo a ANVISA ${ }^{2}$, deve-se pensar na qualidade da técnica de higienização das mãos, evitando o esquecimento de algumas etapas (passo a passo) pois as principais falhas na técnica ocorrem, principalmente, pela não utilização de sabonete e não observação das superfícies das mãos a serem friccionadas, dentre outros.

Quanto a importância de se garantir equipamentos e insumos para a prática de higienização das mãos citada por alguns discentes, sabe-se que reconhecer a importância da higienização das mãos para a prevenção e controle das infecções relacionadas à assistência à saúde é igualmente importante a garantir a estrutura física adequada para a boa prática da higienização das mãos pois o fácil acesso aos insumos e equipamentos pode estimular a higienização das mãos nos serviços de saúde ${ }^{11}$.

Vale ressaltar algumas considerações da Anvisa/ $M^{2}$ : na aquisição de produtos destinados à higienização das mãos deve-se verificar se estes estão registrados na Anvisa/MS, devendo atender às exigências para cada produto. Os lavatórios/ pias devem estar sempre limpos, bem como livres de objetos que dificultem 0 ato de higienizar as mãos. Antes da compra de produtos para higienização das mãos, os dispensadores devem ser avaliados quanto a facilidade de limpeza, liberação de volume suficiente do produto e existência de dispositivos que não favoreça a contaminação do produto, entre outras exigências envolvendo a água, papel toalha de qualidade.

Pesquisa internacional defende que a lavagem das mãos deve tornar-se uma prioridade educacional, reforçando que o profissional de saúde deve servir como um modelo para as futuras gerações de médicos, enfermeiros e outros profissionais ${ }^{12}$. Outra pesquisa sugeriu que mais do que a conscientização do aluno, o docente também deve aderir à Higienização das Mãos (HM) nos momentos oportunos, para também atuar como exemplo e incentivar a prática ${ }^{13}$.

Assim, melhorar a HM deve ser uma prioridade das autoridades de saúde, envolvendo todos os níveis: graduação, pós-graduação ou educação 
continuada, em que existe uma responsabilidade individual de cada profissional da saúde ${ }^{14}$.

Acredita-se que esse estudo tem relevância quando identifica, em parte, as dificuldades para a realização da técnica de higienização das mãos e, isso, poderá servir de norte teórico para se elaborar estratégias durante o acompanhamento dos alunos em campos de prática, bem como elaborar estratégias para que esses dificultadores sejam superados.

\section{CONSIDERAÇÕES FINAIS}

Por meio desse estudo foi possível averiguar, em parte, os saberes relacionados a segurança do paciente dos graduandos de enfermagem. Assim, o diferencial desse estudo está no fato de ter se trabalhado com estudantes do último semestre e a valorização e compreensão dos passos para a segurança do paciente poderão influenciar as práticas assistenciais e de gerenciamento.

Houve valorização pelos acadêmicos de aspectos farmacológicos, o que pode estar associado à prática de administração de medicamentos como uma das maiores responsabilidades da enfermagem, sobretudo do enfermeiro.

O transporte seguro, uso de equipamentos e cirurgia segura foram pouco citados pelos graduandos. Ressalta-se ainda a administração segura de hemocomponentes, que foi pouco lembrada pelos alunos. A higienização das mãos, uso de equipamentos de proteção individual, técnicas assépticas foram citadas como essenciais para a prevenção de infecções relacionadas à assistência à saúde. Não foi evidenciado nas falas, mas é importante discutir, o uso do aparelho celular nos serviços de saúde, visto que, é um objeto que pode servir como veículo de microorganismos, podendo passar despercebido a higienização das mãos depois da utilização do mesmo.

\section{REFERÊNCIAS}

1. Pedreira, Mavilde da Luz Gonçalves.

Enfermagem para a segurança do paciente. Acta paul. enferm. 2009;22(4):v-vi. doi: 10.1590/ S0103-21002009000400001

2. Brasil, Ministério da Saúde. Agência Nacional de Vigilância Sanitária. Segurança do paciente e higienização das mãos. Brasília. DF.

3. Coren- SP. Conselho Regional de Enfermagem do Estado de São Paulo. Rede Brasileira de Enfermagem e Segurança do paciente REBRAENSP. 10 Passos para a segurança do paciente. São Paulo. SP. 2010

4. Belela-Anacleto ASC, Sousa BEC et al. Higienização das mãos e a segurança do paciente: perspectiva de docentes e universitários. Texto Contexto Enferm. 2013;22(4):901-8. doi: $10.1590 /$ S0104-07072013000400005

5. Fontanella BJB, Ricas J, Turato ER. Amostragem por saturação em pesquisas qualitativas em saúde: contribuições teóricas. Cad. Saúde Pública. 2008;24(1):17-27. doi: 10.1590/S0102-

$311 \times 2008000100003$

6. Bardin L. Análise do Conteúdo. Edições 70. Lisboa: 2010.

7. Brasil. Conselho Nacional de Saúde. Resolução CNS No466, de 12 de dezembro de 2012. Dispõe sobre os aspectos éticos da pesquisa envolvendo seres humanos. 2012.

8. Neves ZCP, Tipple AFV, Souza ACS, Melo DS, Ferreira LR, Silva EAC. Relato de experiência: utilização de cartazes estilizados como medida de incentivo à higienização das mãos. Rev. Eletr. Enf. $2009 ; 11(3): 738-45$

\section{Cardoso SR, Pereira LS, Souza ACS, Tipple AFV, Pereira MS, Junqueira ALN. Anti-sepsia para administração de medicamentos por via endovenosa e intramuscular. Rev. Eletr. Enf. $2006 ; 8(1): 75-82$}

10. Kuwabara CCT, Évora YDM, Oliveira MMB. 
Gerenciamento de risco em tecnovigilância: construção e validação de instrumento de avaliação de produto médico-hospitalar. Rev. Latino-Am. Enfermagem. 2010;1 8(5):943-951. doi: 10.1590/S0104-11692010000500015

11. Prado Maria Fernanda do, Hartmann Talita Priscila Scomparin, Teixeira Filho Leône Alberto. Acessibilidade da estrutura física hospitalar para a prática da higienização das mãos. Esc. Anna Nery. 2013;17(2):220-226. doi: 10.1590/S141481452013000200003

12. Mathur P. Hand hygiene: Back to the basics of infection control. The Indian Journal of Medical Research. 2011 ; 134(5):611-620. doi: 10.4103/0971-5916.90985.

13. Martinez J, Roseira CE, Figueiredo RM, Passos IPBD. Higienização das mãos: conhecimento dos estudantes. Ciência, Cuidado e Saúde. 2014;13(3):455-463. doi: 10.4025/ cienccuidsaude.v13i3.19118

14. Škodová M, Gimeno-Benítez A, MartínezRedondo $E$, Morán-Cortés JF, Jiménez-Romano R, Gimeno-Ortiz A. Avaliação da qualidade da técnica de higiene das mãos em alunos de enfermagem e medicina em dois cursos de graduação. Rev. Latino-Am. Enfermagem. 2015;23(4):708-17. doi: 10.1590/01041169.0459 .2607 